\title{
The Bone Does Not Predict the Brain in Sturge-Weber Syndrome
}

\author{
(D)R.R. Warne, DOM. Carney, (D) G. Wang, DD. Bhattacharya, DW.K. Chong, (D) S.E. Aylett, and D K. Mankad
}

\begin{abstract}
BACKGROUND AND PURPOSE: It has been hypothesized that skull marrow signal alteration may represent an early disease manifestation of Sturge-Weber syndrome before development of its intracranial manifestations. We alternatively hypothesized that intraosseous changes are associated with the overlying port-wine stain rather than the intracranial stigmata of Sturge-Weber syndrome and hence are not a predictor of brain involvement.
\end{abstract}

MATERIALS AND METHODS: MR imaging of children presenting with port-wine stain and/or Sturge-Weber syndrome between 1998 and 2017 was evaluated by 2 pediatric neuroradiologists for marrow signal abnormality and pial angioma and other Sturge-Weber syndrome features: ocular hemangioma, atrophy, and white matter changes (advanced myelination). Groups were divided into port-wine stain-only (without intracranial Sturge-Weber syndrome features) and Sturge-Weber syndrome (the presence of cerebral pial angioma). The $\chi^{2}$ test was performed to evaluate the association between port-wine stain and bone marrow changes and between osseous change and pial angioma.

RESULTS: We reviewed 139 cases: 40 with port-wine stain-only and 99 with Sturge-Weber syndrome with pial angioma. Fifteen of 99 cases of Sturge-Weber syndrome had no port-wine stain. In the port-wine stain-only cohort, $78 \%$ had ipsilateral bony changes and $17 \%$ had no intraosseous changes. In the Sturge-Weber syndrome cohort, 84/99 had associated port-wine stain, $91 \%(P<.01)$ had bony changes ipsilateral to the port-wine stain or had no bone changes in the absence of port-wine stain, and $77 \%(P=.27)$ had bony changes ipsilateral to a cerebral pial angioma. Eighty percent of patients with Sturge-Weber syndrome who lacked a port-wine stain also lacked marrow changes. Five patients with bilateral port-wine stain and bilateral marrow changes had only a unilateral pial angioma.

CONCLUSIONS: Intraosseous marrow changes are strongly associated with facial port-wine stain; no significant association was found between pial angioma and bone marrow changes.

ABBREVIATIONS: PWS = port-wine stain; SWS = Sturge Weber syndrome

$\mathbf{P}$ ort-wine stain (PWS) or the synonymous term "port-wine birthmark" is a common vascular anomaly affecting $0.3 \%$ of neonates, and it usually presents as an isolated finding. ${ }^{1}$ For this article, the term "PWS" will be used. A small proportion of PWSs are associated with leptomeningeal angiomatosis and ocular hemangioma, the classic triad of Sturge-Weber syndrome (SWS). Typical features of SWS with gadolinium contrast on MR imaging include enhancing pial angioma, cortical/subcortical atrophy

Received March 1, 2018; accepted after revision May 18.

From the Department of Paediatric Neuroradiology (R.R.W., O.M.C., D.B., W.K.C., K.M.), Great Ormond Street Hospital for Children, NHS Foundation Trust, London, UK; Neurosciences (S.E.A.), Great Ormond Street Hospital for Children and Developmental Neurosciences University College London, NHS Foundation Trust, London UK; Department of Biostatistics (G.W.), University of Sydney School of Public Health, Sydney, New South Wales, Australia 2006.

Please address correspondence to Kshitij Mankad, MBBS, FRCR, Great Ormond Street Hospital for Children, NHS Foundation Trust, Paediatric Neuroradiology, Great Ormond St, London WCIN3JH UK; e-mail: Kshitij.Mankad@gosh.nhs.uk; @Richie_Warne

http://dx.doi.org/10.3174/ajnr.A5722

with calcification, and ocular choroidal enhancement. There are other neuroradiologic features that have been reported in association with SWS, including advanced or accelerated myelination, ${ }^{2}$ prominent transmedullary and cortical veins, ${ }^{3,4}$ and glomus angioma (Fig 1). ${ }^{5}$ For this study, the term "glomus angioma" refers to a venous angioma involving the choroid plexus.

Accelerated or advanced myelination relates to the decreased parenchymal signal on T2WI sequences in the subcortical white matter, which is variably speculated to relate to either calcification, altered myelination states, and/or cerebral blood oxygenation effect. ${ }^{2} \mathrm{~A}$ combination of these mechanisms is likely.

Posterior chamber choroidal hemangiomas may lead to glaucoma by fluid hypersecretion ${ }^{6}$ and may also lead to visual impairment by exudative retinal detachment and macular edema. Choroidal hemangiomas are usually $<6 \mathrm{~mm}$ in thickness ${ }^{7}$ and can be seen in up to $70 \%$ of cases of SWS. ${ }^{8}$ Approximately $50 \%$ of patients with SWS have ocular changes ipsilateral to the PWS. ${ }^{9}$

It has been hypothesized that osseous intramedullary signal 


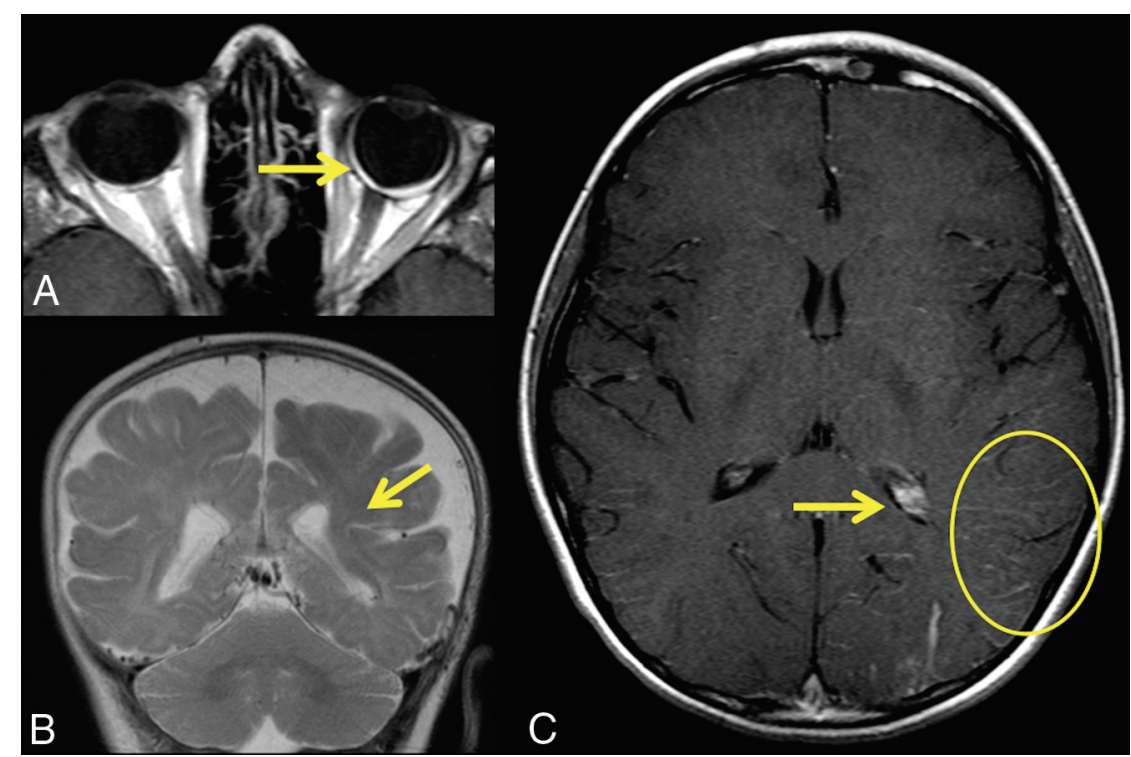

FIG 1. Associated findings of SWS. A 4-month-old boy with SWS. A, Postcontrast TIWI of the orbits shows a left ocular choroidal hemangioma (clinically confirmed). $B$, Coronal T2WI of the brain reveals volume loss of the left hemisphere with associated accelerated myelination (arrow). $C$, Postcontrast axial TIWI of the brain shows an enlarged and enhancing left glomus angioma (arrow) and prominent transmedullary veins (circle).

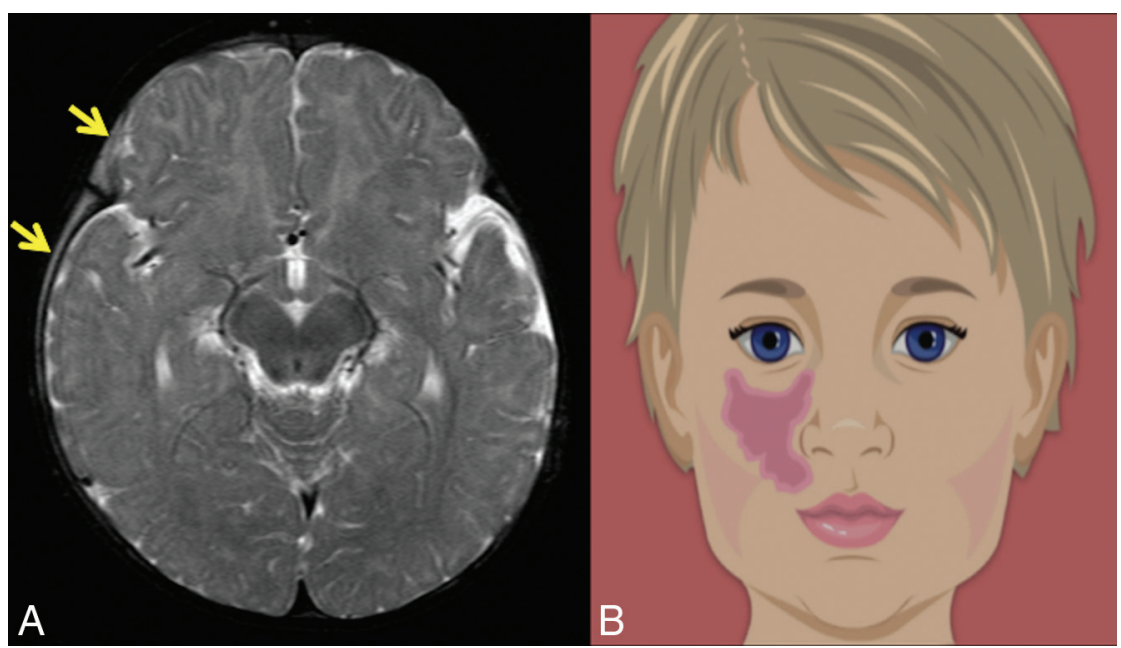

FIG 2. Calvarial bone marrow abnormality. A 6-month-old boy with right PWS only. A, Axial T2-weighted STIR shows high-signal abnormality in the right calvaria (arrows). B, Graphic of a child with right-sided PWS. Reproduced with permission from Scio21/Bigstock.com.

alteration within the skull may represent early disease manifestation of SWS before the development of its intracranial manifestations. ${ }^{10}$ The purpose of our study was to explore and challenge this previously published hypothesis from analysis of a large cohort of children presenting with SWS and/or PWS. We therefore alternatively hypothesized that the osseous changes relate to the overlying PWS (Fig 2) rather than intracranial stigmata of SWS and hence are not a predictor of SWS.

\section{MATERIALS AND METHODS}

This project was approved by the institutional research board (reference number 2045). The cohort for the study comprised all patients referred to the department of neuroradiology at a tertiary children's hospital between 1998 and 2017 for imaging assessment of suspected
SWS. The criterion for referral was clinical or dermatologic: the presence of a facial PWS or clinical suspicion of SWS in those patients in whom a PWS was absent.

All patients had $\geq 1$ MR imaging brain scan, including gadolinium-enhanced T1WI sequences. A standardized protocol using a 1.5T scanner (Symphony or Avanto; Siemens, Erlangen, Germany) or a 3T Magnetom Prisma scanner (Siemens) was used for imaging performed at our center.

If the patients were younger than 24 months of age, the protocol included the following: axial dual-echo STIR inversion recovery with T1weighted axial, coronal, sagittal postgadolinium, and DWI sequences. For patients older than 24 months of age, the axial dual-echo STIR was replaced by an axial T2WI and FLAIR.

Of note, 56 scans $(40 \%$ of the imaging) had been obtained at the patient's local radiology department, and the imaging was transferred electronically for a second opinion to our institution. Each study was evaluated for the presence of calvarial marrow change, marrow or dural thickening or enhancement, and stigmata of SWS intracranial findings, including cerebral pial angioma, choroidal hemangioma, glomus angioma, transmedullary and prominent cortical veins, and accelerated myelination. Cortical calcification and mineralization were not routinely recorded because not all studies had dedicated sequences. However, if the study had a recent CT or a susceptibilityweighted MR imaging sequence that confirmed calcification, it was noted. The essential criterion in the PWS-only group was the presence of a facial PWS and the absence of any intracranial findings (cerebral changes or pial angioma). The inclusion criterion of the SWS group was the presence of a pial angioma.

The clinical notes were reviewed following the imaging analysis to obtain the neurologic and ophthalmologic details; when possible, clinical photography records were reviewed to determine the side of the PWS distribution.

Patients were excluded from analysis if the site of the PWS was not available as per clinical records or their imaging was unavailable, they did not have a contrast scan, or they had a crossover syndrome (eg, Klippel-Trenaunay syndrome).

\section{Statistics}

$\chi^{2}$ and Fischer exact tests were used to evaluate the association between PWS and intraosseous change and, in addition in the SWS 


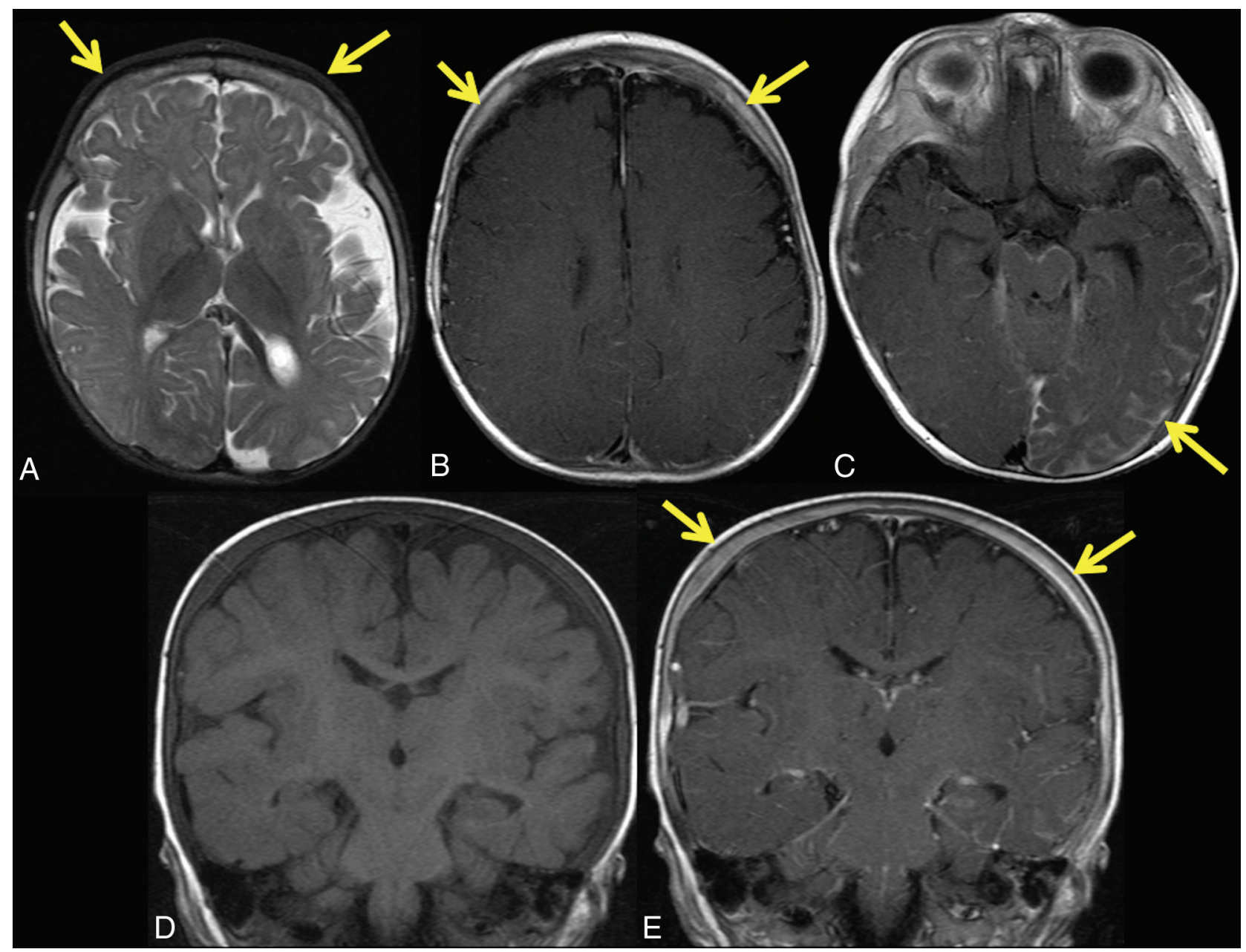

FIG 3. Bilateral PWS with bilateral calvarial marrow abnormality. An 8-month-old boy with SWS. Axial T2-weighted-STIR (A) and axial TI-weighted postcontrast (B) images reveal a bilateral marrow T2 high-signal calvarial abnormality and enhancement. $C$, Axial TWWI postcontrast shows a left-sided temporo-occipital pial angioma. Coronal T7-weighted precontrast $(D)$ and postcontrast $(E)$ imaging show bilateral marrow and dural enhancement.

Intraosseous signal abnormality versus same-sided PWS

\begin{tabular}{ccc}
\hline & \multicolumn{3}{c}{$\begin{array}{c}\text { Intraosseous } \\
\text { Signal Abnormality }\end{array}$} \\
\cline { 2 - 3 } PWS & Present & Absent \\
\hline Present & 109 & 10 \\
Absent & 3 & 12 \\
\hline
\end{tabular}

group, the association between the intraosseous change and the pial angioma.

\section{RESULTS}

In total, 139 cases were included (40 patients with PWS only and 99 patients with SWS).

\section{PWS-Only Group}

The PWS-only group ( $n=40)$ comprised an even distribution of 20 male and 20 female patients, with ages ranging from 10 weeks to 13.5 years (mean, 2.4 years).

\section{PWS and Intraosseous Change Relationship}

Of the 40 patients in the PWS-only group, 31 (78\%) had concordant bone marrow changes ipsilateral to the PWS. Seven patients (18\%) had absent bone marrow changes, with the remaining 2

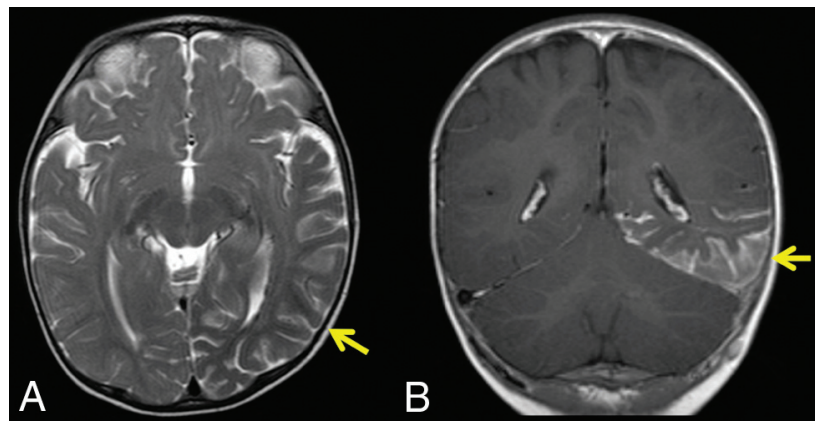

FIG 4. SWS with absent PWS. An 8-month-old girl with SWS. A, Axial T2-weighted STIR shows left temporo-occipital calvarial thinning with no bone marrow abnormality. B, Axial postcontrast TTWI shows a corresponding thick enhancing left hemispheric pial angioma.

cases revealing bilateral changes from a unilateral PWS. All 31 concordant intraosseous changes had associated intraosseous/dural enhancement and/or thickening noted.

\section{SWS Group}

The SWS group $(n=99)$ included 45 male and 54 female patients, ranging from 1 day to 14.5 years of age (mean, 2.4 years). Of the 99 patients with SWS, 84 had associated PWS.

AJNR Am J Neuroradiol 39:1543-49 Aug 2018 www.ajnr.org 


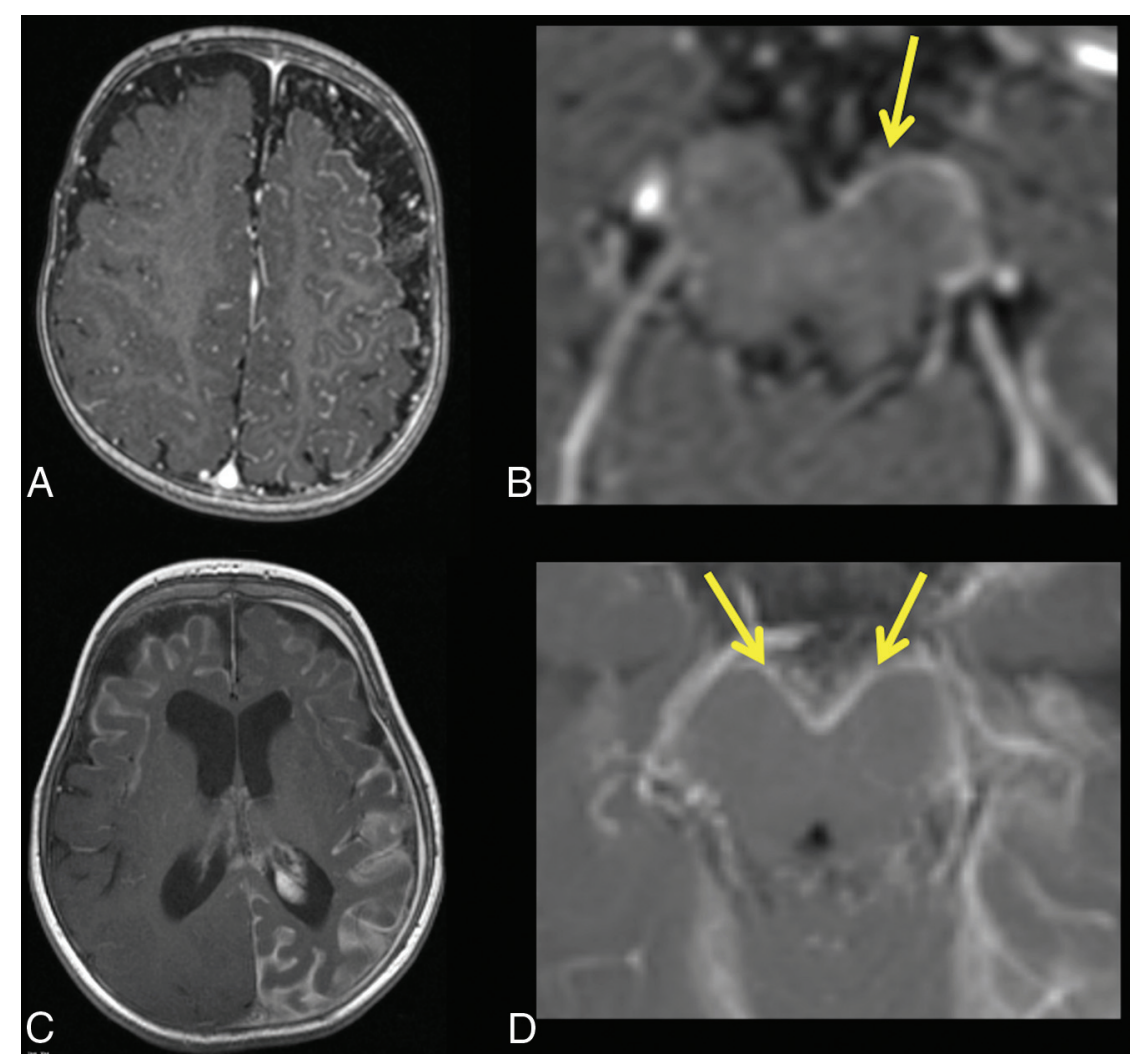

FIG 5. The interpeduncular cistern sign. Upper panel, a 9-month-old boy with SWS. $A$ and $B$, Postcontrast axial TIWI shows a left-sided unilateral pial angioma and a zoomed-in view of the interpeduncular cistern confirming the unilaterality (arrow). Lower panel, a 10-month-old girl with SWS. $C$ and $D$, Bilateral pial angiomas with a zoomed-in view confirming the bilaterality (arrows), positive for the "warning sign of Warne-Mankad."
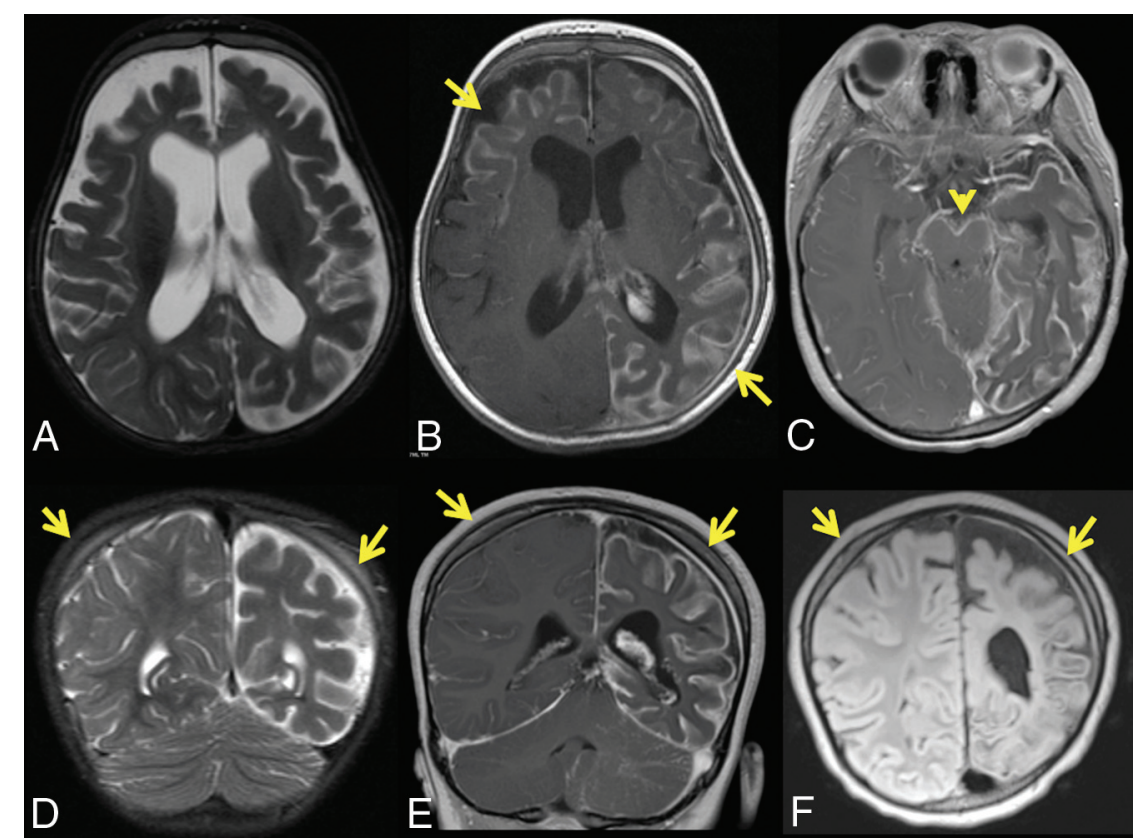

FIG 6. "Warning sign of Warne-Mankad." Bilateral interpeduncular cistern enhancement. A 10month-old girl with SWS and bilateral PWS. A, Axial T2-weighted STIR shows bilateral hemispheric volume loss. B, Axial postcontrast TIWI shows a right-frontal and left-hemispheric pial angioma with the warning sign confirming the bilateral interpeduncular cistern enhancement (C). Coronal T2-weighted STIR $(D)$ shows bilateral calvarial high signal and marrow enhancement $(E)$. Coronal postcontrast FLAIR image $(F)$ shows bilateral marrow enhancement and left-sided dural thickening.

\section{PWS and Intraosseous Change} Relationship in the SWS Group

Of the 99 patients in the SWS group, 90 $(91 \%, P<.01)$ had concordant intraosseous changes ipsilateral to the PWS (Fig 3) or absent if they did not have a PWS (Table). Of the 84 patients with PWS, 78 (93\%) had concordance between the PWS and intraosseous change, with 76 of these having associated intraosseous/dural enhancement or thickening (Fig 3).

\section{Pial Angioma Side and Intraosseous Change Relationship}

The association between the side of the pial angioma and marrow change was also documented. All 99 patients in the SWS group had a pial angioma; 76 of the $99(77 \%)(P>.05)$ cases were concordant with the pial angioma and intraosseous change side. Of note, 12/15 (80\%) patients with SWS who lacked a PWS also lacked marrow signal changes (Fig 4), while the remaining 3 cases revealed bony changes ipsilateral to the leptomeningeal angioma. In 6 of the 76 patients $(8 \%)$ with concordant pial angioma and intraosseous change, the pial angioma was distant from the marrow abnormality.

\section{Additional Observation}

Five patients with bilateral PWS and bilateral marrow changes only had a unilateral pial angioma rendering further support to our hypothesis.

\section{Associated SWS Imaging Features}

In the PWS-only group, 0/40 had an associated SWS imaging feature. In the SWS group, 36/99 (36\%) had accelerated myelination.

\section{Intraosseous/Dural Enhancement and/or Thickening}

In the PWS-only group, 31/40 had intraosseous/dural enhancement and/or thickening. Eighty-five of 99 patients with SWS had intraosseous/dural enhancement or thickening.

\section{Ocular Hemangioma}

In the PWS-only group, 9 of the 40 (23\%) patients had ocular choroidal enhancements, all of which were ipsilateral to the PWS. Eight of these were ipsilateral to the bone marrow abnormality; the other 


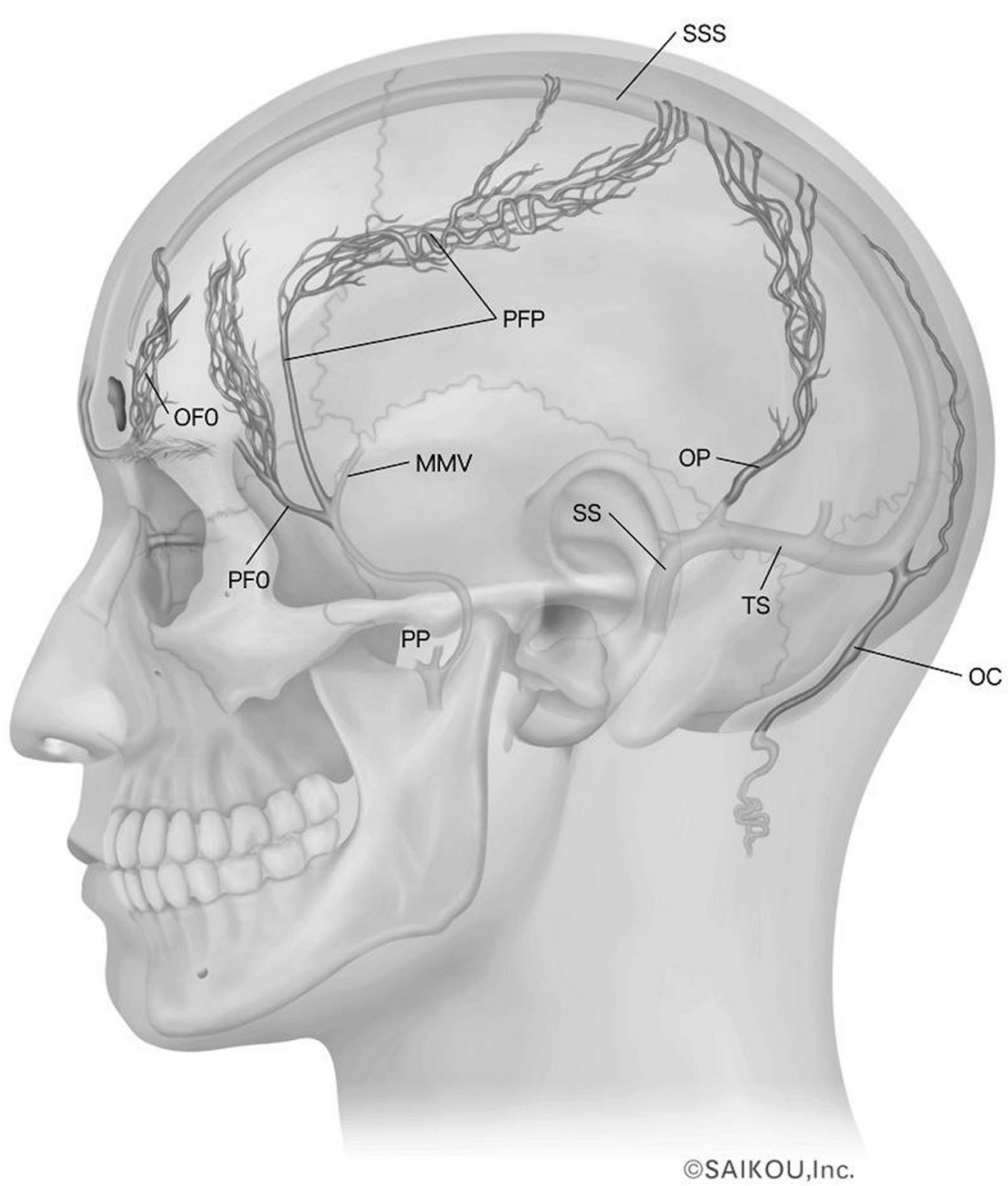

FIG 7. Schematic illustration of the major calvarial diploic venous channel routes over the skull. Reproduced with permission from Springer Nature (Tsutsumi et $\mathrm{al}^{16}$ ). MMV indicates middle meningeal vein; OC, occipitocervical route; OFO, orbital part of the fronto-orbital route; OP, occipitoparietal route; PFO, pterional part of the fronto-orbital route; PFP, pteriofrontparietal route; PP, pterygoid plexus; SS, sigmoid sinus; SSS, superior sagittal sinus; TS, transverse sinus.

one had absent bone marrow change. In the SWS group, 58 of the 99 (59\%) patients had ocular choroidal enhancement. Three of these had an absent PWS. The remaining 55 patients had ocular enhancement ipsilateral to the PWS and pial angioma side. Of the absentPWS SWS group, 3/15 had a choroidal hemangioma.

\section{Glomus Angioma}

In the PWS-only group, 0/40 had glomus angioma. In the SWS group, 80/99 (81\%) had glomus angioma.

\section{Atrophy}

In the PWS-only group, 0/40 had atrophy. In the SWS group, $63 / 99$ (64\%) had atrophy. Eight patients had associated cortical calcification (gradient dataset or on CT when available).

\section{Prominent Transmedullary Veins}

In the PWS-only group, $0 / 40$ had prominent transmedullary veins. In the SWS group, 78/99 (79\%) had prominent transmedullary veins.

\section{Unusual Pial Angioma Imaging Appearances}

Interpeduncular Cistern Location. Twelve of 99 patients had an interpeduncular cistern (posterior fossa) location for the pial angioma. Most interesting, of those 12, three of the 4 patients with a unilateral PWS had a pial angioma, which did not cross the midline (Fig 5A, - B), while the remaining 8 patients had bilateral PWS with interpeduncular cistern enhancement crossing the midline (Fig $5 C,-D$ ). We called this type of $\mathrm{W}$-shaped enhancement the "warning sign of Warne-Mankad" after this phenomenon and propose this as a review area for subtle pial angiomas as well as a predictor of bilateralism.

\section{DISCUSSION \\ About SWS}

Sturge-Weber syndrome is a rare congenital neurovascular disorder (estimated at 1:50,000) characterized by the triad of facial capillary malformation (port-wine stain), ocular choroidal hemangioma, and leptomeningeal (pial) angioma. SWS and nonsyndromic PWS are caused by somatic activating mutations in the GNAQ gene located on chromosome 19q21, affecting early fetal vascular development. ${ }^{11}$ A recent study ${ }^{12}$ suggested that the strongest predictor of SWS is based on a classification of PWS considering the vascular embryologic distribution. The best predictor of adverse outcomes is a PWS involving any part of the forehead, delineated at its inferior border by a line joining the outer canthus of the eye to the top of the ear, including the upper eyelid.

The Roach classification has been used to classify patients with SWS into 3 groups ${ }^{13}$ : type 1, facial PWS and leptomeningeal angioma (classic); type 2, facial PWS alone; and type 3, isolated leptomeningeal angioma.

Other authors have however considered the diagnosis of SWS to apply only when there is a typical contrast-enhancing leptomeningeal angioma. ${ }^{14}$

Our SWS group had $25 \%$ of patients with bilateral pial angiomas (Fig 6); the rest were unilateral. The typically associated imaging findings within this group were glomus angioma $(81 \%)$, prominent transmedullary veins (79\%), atrophy $(64 \%)$, accelerated myelination (36\%), and cortical calcification $(8 \%)$. The relatively low yield of cortical/subcortical calcification was most likely due to the lack of calcium-specific imaging.

A lesser known finding in SWS is the intraosseous signal abnormality, previously described as related to the pial angioma and 
hence an early predictor of brain involvement when other findings are absent.

The calvaria is a site for diffuse hematopoietic marrow activity with the vascular supply of marrow largely from nutrient arteries and an extensively anastomosing venous plexus. Birthmarks and vascular lesions are known to have adjacent skeletal marrow changes. ${ }^{15}$ We hypothesize that the facial PWS drains into the calvarial diploic system and, in particular, the pteriofrontparietal and fronto-orbital pathways ${ }^{16}$ (Fig 7); this feature would then result in the intraosseous signal change.

The cases in this study were age-matched for normal signal because in the infant and young child, red marrow comprises $40 \%$ water, $40 \%$ fat, and $20 \%$ protein. There are changes in these constituents with age, with an increase in fat and decrease in water and protein in the adult. ${ }^{17}$

Both PWS-only and SWS groups were similarly matched in a nearly equal male/female distribution with similar mean ages and ranges. The comparison of nearly equally matched patient demographics between these 2 groups is a study strength, especially compared with the previous literature. ${ }^{10}$

This is a cross-sectional study in which 139 subjects had PWS and/or diagnosed SWS. Of the 139 cases, 114 had both port-wine stain and marrow edema. Of these 114 cases, 5 had PWS on the opposite side of marrow edema, while 109 had PWS and marrow edema on the same side.

On the basis of the calculation using a total of 139 patients who had PWS and/or diagnosed SWS, we detected a statistically significant association between marrow edema and PWS with a relative risk of 4.58 (95\% CI, 1.67-12.7; $P<.05)$. This association is present regardless of the marrow edema and PWS being on the same side or opposite each other.

We performed a subgroup analysis by excluding the 5 patients who had PWS on the opposite side of the marrow edema. We detected a statistically significant association between marrow edema and same-sided PWS. The relative risk was 4.58 (95\% CI, $1.66-12.6 ; P<.05)$.

In other words, in patients with PWS or diagnosed SWS, marrow edema and PWS are 4.6 times more likely to be coexistent than not. This supports our hypothesis that the bone marrow change is not reflective of developing a pial angioma but corresponds to the skin change. There was no statistically significant association identified between the intraosseous bone marrow change and pial angioma (95\% CI, 0.49-3.9; $P>.05)$.

Most interesting, an ocular choroidal hemangioma being seen in patients without a pial angioma suggests further that it may also relate more strongly to the presence of PWS.

For this study, choroidal enhancement has been described as choroidal hemangioma. We note however that there is controversy in the published literature as to the exact nature of the ocular lesion, and some authors have described it as a choroidal capillary malformation. ${ }^{18}$ Our analysis revealed that $23 \%$ of the PWS-only and 59\% of the SWS group had this finding. Our study, therefore, shows that the ocular findings can be seen with isolated PWS and in association with SWS.

\section{Similarities with Meningioangiomatosis}

Of the 15 cases of SWS with absent PWS, 14 had a thick pial angioma that filled the adjacent subarachnoid space and are similar to previously published case reports. ${ }^{19}$ These appearances are not typical for a SWS pial angioma but similar to some of the imaging descriptions of meningioangiomatosis. ${ }^{20}$

\section{About PWS}

PWSs are low-flow malformations of dermal capillaries and postcapillary venules, present at birth, that do not regress with time. With age, they grow in proportion to the patient's size and become thicker and darker in adulthood.

\section{Role of Imaging and Contrast}

MR imaging should be performed with contrast T1-weighted imaging to visualize the leptomeningeal angioma and to determine its extent and laterality. Associated findings of ocular choroidal hemangioma, glomus angioma, and prominent draining veins are also better visualized on a contrast scan. Contrast-enhanced FLAIR has also been shown to improve the conspicuity of leptomeningeal angioma. ${ }^{21}$ If an unenhanced study in the neonate without contrast has been performed, a repeat study at 1 year of age to exclude the pial angioma should be performed.

\section{CONCLUSIONS}

Bone marrow changes are strongly associated with the presence of facial port-wine stain. No significant association was found between the presence or development of a pial angioma and bone marrow changes. On the basis of our imaging findings, we conclude that the calvarial intraosseous marrow abnormality is related to the cutaneous PWS and is not a predictor of intracranial SWS.

Disclosures: Sarah E. Aylett—UNRELATED: Board Membership: EXIST 3 Advisory Board, Comments: 2016, organized by Novartis in relation to the everolimus trial; Payment for Manuscript Preparation: Payment for writing the article with a coauthor; Comments: "Tuberous Sclerosis Complex: From Child to Adult," published January 1, 2016, in Key Opinions in Medicine (Wiley).

\section{REFERENCES}

1. Kanada KN, Merin MR, Munden A, et al. A prospective study of cutaneous findings in newborns in the United States: correlation with race, ethnicity, and gestational status using updated classification and nomenclature. J Pediatr 2012;161:240-45 CrossRef Medline

2. Lin DD, Barker PB, Kraut MA, et al. Early characteristics of SturgeWeber syndrome shown by perfusion MR imaging and proton MR spectroscopic imaging. AJNR Am J Neuroradiol 2003;24:1912-15 Medline

3. Mittal S, Wu Z, Neelavalli J, et al. Susceptibility-weighted imaging: technical aspects and clinical applications, Part 2. AJNR Am J Neuroradiol 2009;30:232-52 CrossRef Medline

4. Adams ME, Aylett SE, Squier W, et al. A spectrum of unusual neuroimaging findings in patients with suspected Sturge-Weber syndrome. AJNR Am J Neuroradiol 2009;30:276-81 CrossRef Medline

5. Smirniotopoulos JG. Neuroimaging of phakomatoses: Sturge-Weber syndrome, tuberous sclerosis, von Hippel-Lindau syndrome. Neuroimaging Clin N Am 2004;14:171-83, vii CrossRef Medline

6. Sharan S, Swamy B, Taranath DA, et al. Port-wine vascular malformations and glaucoma risk in Sturge-Weber syndrome. J AAPOS 2009;13:374-78 CrossRef Medline 
7. Singh $\mathrm{AD}$, Kaiser PK, Sears JE. Choroidal hemangioma. Ophthalmol Clin North Am 2005;18:151-61, ix CrossRef Medline

8. Arora KS, Quigley HA, Comi AM, et al. Increased choroidal thickness in patients with Sturge-Weber syndrome. JAMA Ophthalmol 2013;131:1216-19 CrossRef Medline

9. Mantelli F, Bruscolini A, La Cava M, et al. Ocular manifestations of Sturge-Weber syndrome: pathogenesis, diagnosis, and management. Clin Ophthalmol 2016;10:871-78 CrossRef Medline

10. Whitehead MT, Vezina G. Osseous intramedullary signal alteration and enhancement in Sturge-Weber syndrome: an early diagnostic clue. Neuroradiology 2015;57:395-400 CrossRef Medline

11. Shirley MD, Tang H, Gallione CJ, et al. Sturge-Weber syndrome and port-wine stains caused by somatic mutation in GNAQ. $N$ Engl J Med 2013;368:1971-79 CrossRef Medline

12. Waelchli R, Aylett SE, Robinson K, et al. New vascular classification of port-wine stains: improving prediction of Sturge-Weber risk. Br J Dermatol 2014;171:861-67 CrossRef Medline

13. Roach ES. Neurocutaneous syndromes. Pediatr Clin North Am 1992; 39:591-620 CrossRef Medline

14. Comi AM. Presentation, diagnosis, pathophysiology, and treatment of the neurological features of Sturge-Weber syndrome. Neurologist 2011;17:179-84 CrossRef Medline
15. Boyd JB, Mulliken JB, Kaban LB, et al. Skeletal changes associated with vascular malformations. Plast Reconstr Surg 1984;74:789-97 CrossRef Medline

16. Tsutsumi S, Nakamura M, Tabuchi T, et al. Calvarial diploic venous channels: an anatomic study using high-resolution magnetic resonance imaging. Surg Radiol Anat 2013;35:935-41 CrossRef Medline

17. Chan BY, Gill KG, Rebsamen SL, et al. MR imaging of pediatric bone marrow. Radiographics 2016;36:1911-30 CrossRef Medline

18. Sullivan TJ, Clarke MP, Morin JD. The ocular manifestations of the Sturge-Weber syndrome. J Pediatr Ophthalmol Strabismus 1992;29: 349-56 Medline

19. Siri L, Giordano L, Accorsi P, et al. Clinical features of Sturge-Weber syndrome without facial nevus: five novel cases. Eur J Paediatr Neurol 2013;17:91-96 CrossRef Medline

20. Nascimento FA, Kiehl TR, Tai PC, et al. Meningioangiomatosis: a disease with many radiological faces. Can J Neurol Sci 2016;43: 847-49 CrossRef Medline

21. Lee EK, Lee EJ, Kim S, et al. Importance of contrast-enhanced fluidattenuated inversion recovery magnetic resonance imaging in various intracranial pathologic conditions. Korean J Radiol 2016;17: 127-41 CrossRef Medline 